\title{
Synaptic integration in the deep cerebellar nuclei: comparing dynamic clamp results with a computer model of somatic or distributed dendritic input
} Risa Lin*1, Svenja Metz ${ }^{2}$ and Dieter Jaeger ${ }^{3}$

Address: ${ }^{1}$ Department of Biomedical Engineering, Georgia Institute of Technology, Atlanta, GA 30332, USA, ${ }^{2}$ Department of Biomedical Engineering, University of Applied Sciences Lübeck, Lübeck, Germany and ${ }^{3}$ Department of Biology, Emory University, Atlanta, GA 30332, USA

Email: Risa Lin* - risa@gatech.edu

* Corresponding author

from Seventeenth Annual Computational Neuroscience Meeting: CNS*2008

Portland, OR, USA. 19-24 July 2008

Published: II July 2008

BMC Neuroscience 2008, 9(Suppl I):OI2 doi:10.1 186/147I-2202-9-SI-OI2

This abstract is available from: http://www.biomedcentral.com//47I-2202/9/SI/OI2

(C) 2008 Lin et al; licensee BioMed Central Ltd.

Dynamic clamping is an increasingly popular method to apply artificial conductances to neurons. Many studies use this method to apply in-vivo like synaptic input patterns to neurons recorded in brain slices. The major drawback of this method is that conductances can only be applied at a single location, usually the soma, and thus may not replicate the effect of distributed conductances naturally present in the neuron. We examined the consequences of 'focalizing' distributed synaptic input in a morphologically realistic compartmental model of a deep cerebellar nucleus (DCN) neuron. We applied the exact synaptic conductance patterns we previously used in dynamic clamp studies $[1,2]$ in our computer model either only at the soma to simulate dynamic clamping, or distributed throughout the dendritic tree to simulate natural synaptic input in vivo. We varied the synchronicity of synaptic inputs and used different gain factors to explore a range of input conductance amplitudes. Somatic current noise was included in order to produce variable spike times with repeated stimulation. We were able to replicate our dynamic clamp results with respect to spike rates and spike precision for different gains and levels of synchrony with either focal or distributed input in the model (Fig 1). We find that only minor differences exist in the spike pattern generation for focal or distributed input in this cell type. The similarity of the results is explained by the electrotonically compact structure of DCN neurons, which led to a similar level of dendritic voltage-gated currents for both input conditions. In fact, a reduced 6-compartment model was also able to replicate the experimental findings with dynamic clamp. Furthermore, the model replicated the effects of pharmacological Sk channel block on synaptic integration. These results highlight the ability to study the interaction of intrinsic properties and synaptic input in the control of output spiking with a combined dynamic clamp and modeling approach. 


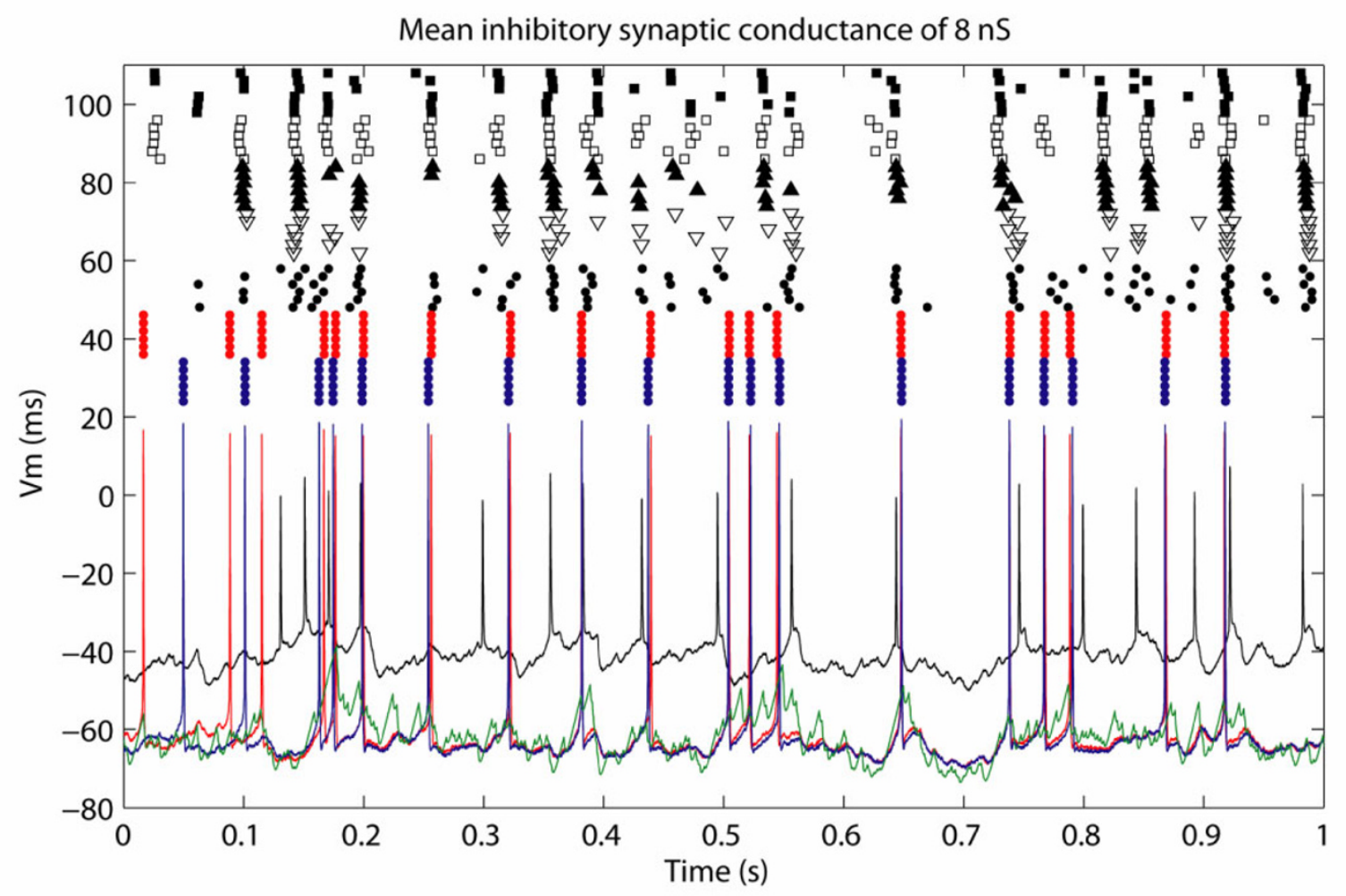

Figure I

Comparison of voltage traces from dynamic clamp experiments (black), simulation of dynamic clamp with focalized synaptic input (red), and distributed synaptic input (blue) with the synaptic driving force (green). Raster plots are shown for five different cells under dynamic clamp and simulations including somatic current noise.

\section{References}

I. Gauck V, Jaeger D: The control of rate and timing of spikes in the deep cerebellar nuclei by inhibition. I Neurosci 2000 , 20(8):3006-30I6.

2. Gauck $V$, jaeger $D$ : The contribution of NMDA and AMPA conductances to the control of spiking in neurons of the deep cerebellar nuclei. J Neurosci 2003, 23(22):8109-8II8.

Publish with Bio Med Central and every scientist can read your work free of charge

"BioMed Central will be the most significant development for disseminating the results of biomedical research in our lifetime. "

Sir Paul Nurse, Cancer Research UK

Your research papers will be:

- available free of charge to the entire biomedical community

- peer reviewed and published immediately upon acceptance

- cited in PubMed and archived on PubMed Central

- yours - you keep the copyright
BioMedcentral 